\title{
Acute complications of elective coronary angioplasty: a review of 500 consecutive procedures
}

\author{
G STEFFENINO, * B MEIER, L FINCI, V VELEBIT, L voN SEGESSER, \\ B FAIDUTTI, W RUTISHAUSER \\ From the Cardiology Centre and Division of Cardiac Surgery, University Hospital, Geneva, Switzerland
}

SUMMARY In 500 consecutive procedures of elective coronary angioplasty attempted at a centre with a primary success of $86 \%$, one or more major acute complications occurred in 34 cases $(6 \cdot 8 \%)$. Twenty four patients $(4 \cdot 8 \%$ ) sustained an acute myocardial infarction (in six this was despite emergency coronary artery bypass surgery) and two patients $(0.4 \%)$ had emergency coronary bypass without myocardial infarction. Ventricular fibrillation was a complication without sequelae in five $(1.0 \%)$ patients; one $(0.2 \%)$ patient died because of refractory ventricular fibrillation and ensuing electromechanical dissociation. "Benign" coronary artery rupture occurred in one $(0 \cdot 2 \%)$ patient, and one $(0.2 \%)$ patient had elective coronary surgery to retrieve the tip of a fractured guide wire after an otherwise successful angioplasty.

Despite a low mortality, coronary angioplasty is associated with major complications in about one of 14 procedures; the complication is usually acute myocardial infarction caused by occlusion of the vessel.

Since the introduction of percutaneous transluminal coronary angioplasty by Gruentzig in $1977^{1}$ there has been considerable interest in the benefits and complications of this technique. ${ }^{23}$ Reports of complications came from large series, but in many of these reports the results were influenced by the early use of non-steerable dilatation systems. ${ }^{4-8}$ The first phase of the operators' learning curve $e^{9}$ was included when smaller series were pooled. ${ }^{78}$ Other very large series are based on the results of several operators working in a single large institution with a heavy case load. ${ }^{10}$

This paper analyses the major complications encountered in a series of 500 consecutive procedures of elective percutaneous transluminal coronary angioplasty with steerable dilatation systems. The procedures were performed by, or in cooperation with, one interventional cardiologist with considerable training and experience in percutaneous transluminal coronary angioplasty. Data from this study may be relevant to other centres where percutaneous

Requests for reprints to Dr B Meier, Centre de Cardiologie, Hôpital Cantonal Universitaire, CH-1211 Geneva 4, Switzerland.

^Present address: Istituto di Medicina e Chirurgia Cardiovascolare Università di Torino, Turin, Italy.

Accepted for publication 2 August 1987 transluminal coronary angioplasty is being initiated according to recently recommended standards. ${ }^{11}$

\section{Patients and methods}

Between July 1983 and January 1986, 500 consecutive procedures of elective percutaneous transluminal coronary angioplasty were attempted at our centre by, or under supervision of, a staff cardiologist with an extensive training in percutaneous transluminal coronary angioplasty. There were 430 men $(86 \%)$ and 70 women (mean (SD) age 55 (9) years, range $23-76$ years). In 110 cases $(22 \%)$ the patient was in New York Heart Association class IV for angina.

A common strategy was followed in all procedures: no lesion on a vessel supplying collateral flow to another vessel was attempted until the latter had been revascularised, except when the amount of viable myocardium in the corresponding territory was presumed to be insignificant. Recanalisation of chronic occlusion in the presence of viable myocardium was attempted when the presumed duration of occlusion was $<6$ months. When patients with two or three vessel disease had stable angina they were considered as candidates for percutaneous transluminal coronary angioplasty if all the important lesions were suitable for dilatation and when they had 
unstable angina they were regarded as candidates if one critical lesion that was suitable for percutaneous transluminal coronary angioplasty could be clearly identified as being responsible for the symptoms and electrocardiographic signs of acute ischaemia.

All procedures were performed by the transfemoral route, with steerable dilatation systems (Schneider Shiley, Zurich, Switzerland). The details of the technique have been described elsewhere. ${ }^{12}$ Intravenous heparin (10 $000 \mathrm{IU})$ was given after the femoral sheath was in position and an additional 5000 IU was given an hour later if the procedure had not been completed by then. Intracoronary nifedipine $(0.1 \mathrm{mg})$ and isosorbide dinitrate $(0.2 \mathrm{mg})$ were given before dilatation and repeat doses were often given after balloon inflation. The femoral sheaths were usually removed in the ward 4-8 hours after the procedure, but they were sometimes left in place for up to 48 hours when the results were equivocal. Continuous intravenous infusions of isosorbide dinitrate and heparin were used and access for follow up coronary angiography or a repeat procedure was deemed necessary.

When there was acute occlusion of the dilated vessel in the catheterisation laboratory emergency recanalisation was attempted by repeat percutaneous transluminal coronary angioplasty, and if thrombus was present intracoronary streptokinase was also given. Intracoronary isosorbide dinitrate or nifedipine or both were given freely to counteract coronary spasm. When patients already in the ward developed signs or symptoms of acute ischaemia a follow up coronary arteriogram was obtained if the identity of the responsible vessel was uncertain, or if emergency recanalisation seemed feasible. Emergency coronary bypass surgery (within 12 hours) was performed when major signs and symptoms of acute ischaemia developed after the occlusion of an impor- tant vessel in which percutaneous recanalisation ${ }^{-}$ could not be attempted or had been unsuccessful. $\overrightarrow{\overrightarrow{0}}$

All coronary stenoses were evaluated before an $\Phi^{5}$ after percutaneous transluminal coronary angio $\frac{}{0}$ plasty by visual estimation in all available projections. by two independent angiographers and results werep averaged. Intimal dissection was defined as the presence of an intimal flap with a double lumen? contour or persistent staining of the vessel wall byp contrast material. Acute occlusion of the dilated vessel was defined as an appreciable worsening in vessel patency with a severe impairment of distaß̧ progression of contrast. Primary success was defined as an improvement in the angiographic appearance of at least the ischaemia-related lesion, and of the transstenotic gradient whenever available, with nor residual stenosis of $>50 \%$, in the absence of acuter myocardial infarction or the need for emergency coronary surgery, and in the presence of a clinicali improvement in angina of at least one class. Myocar $-\frac{\mathbb{D}}{7}$ dial infarction was defined as an increase in plasmक्के creatine kinase ( $>280 \mathrm{U} / \mathrm{l}$ ) and an $\mathrm{MB}$ fraction of $\geqslant 10 \%$ of total creatine kinase. Plasma creatine kinase concentrations were routinely assessed abou $\mathscr{E}^{\circ}$ eight hours after the procedure, and every six hours thereafter (if the initial findings were abnormal) untip a peak was reached. Electrocardiograms were routin ely recorded immediately after the procedure and the next morning. Tracings at discharge were obtaine ${ }^{2}$ in patients with complications.

Data are expressed as mean $(\mathrm{SD})$ values. We use $\overrightarrow{\vec{\phi}}$ Student's $t$ test and the $\chi^{2}$ test as appropriate; $p$ values of $<0.05$ were regarded as significant.

\section{Results}

In 500 consecutive procedures 590 vessels werę attempted. The Table shows the vessel distribution.

Table Distribution of vessels dilatated and frequency of acute coronary vascular events

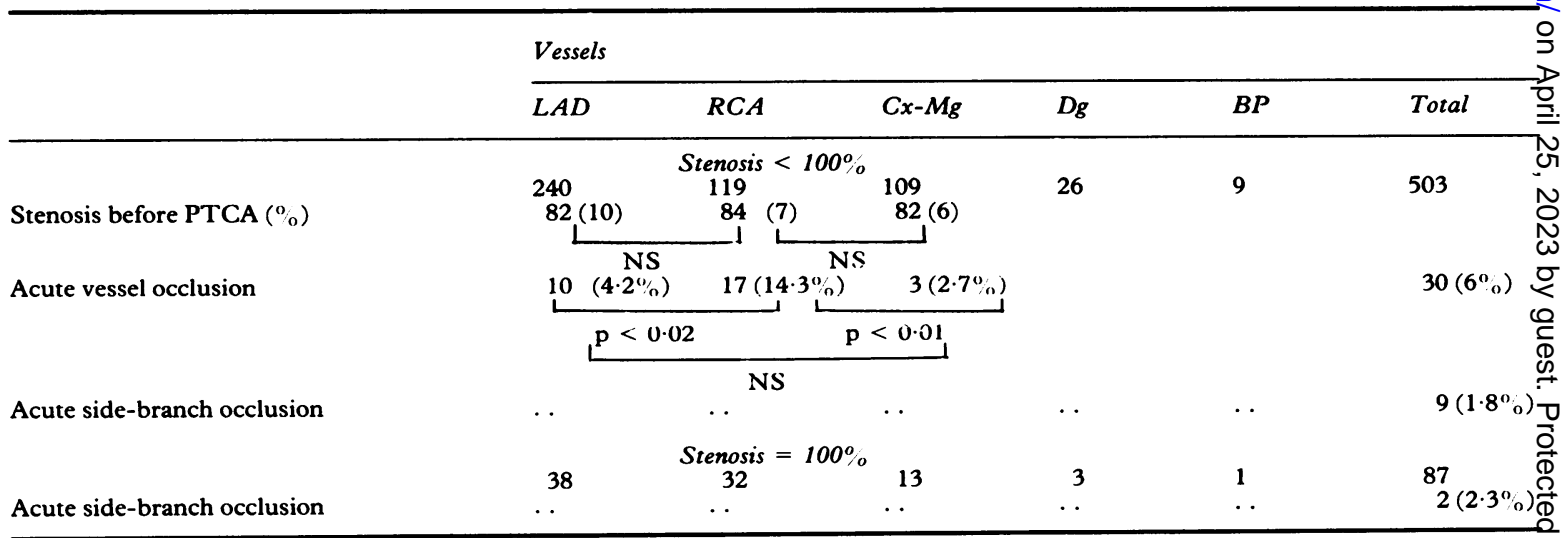

$\overline{\mathrm{BP}}$, bypass graft; $\mathrm{Dg}$, diagonal branch; $\mathbf{C x}-\mathbf{M g}$, circumflex coronary artery or marginal branch; LAD, left anterior descending coronary artery; PTCA, percutaneous transluminal coronary angioplasty; RCA, right coronary artery. 

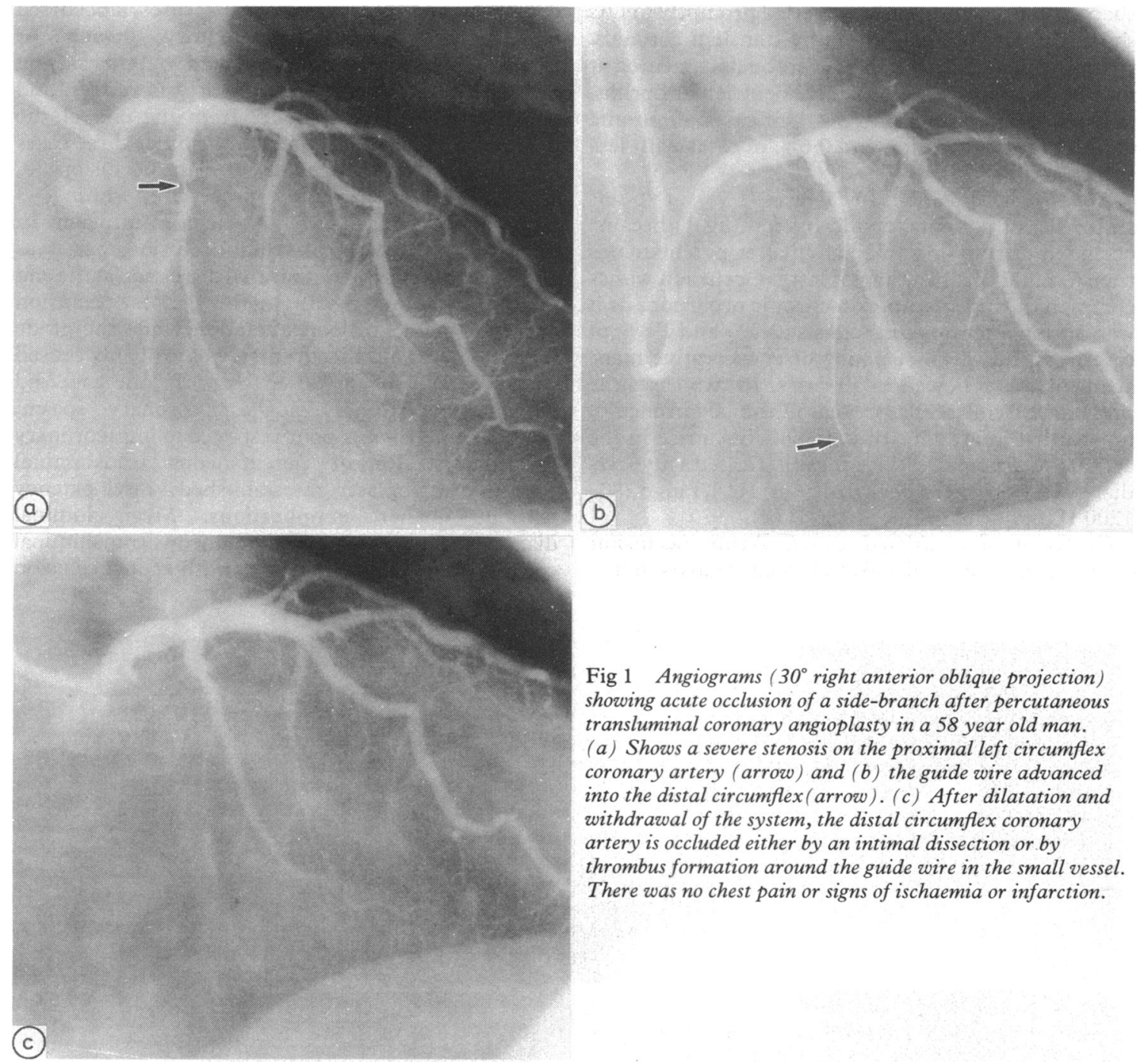

and the frequency of occlusive complications. Two vessels were attempted in 80 cases and three vessels in five cases: multivessel percutaneous transluminal coronary angioplasty was attempted in $17 \%$ of cases. In 87 cases $(17 \%)$ recanalisation of a chronic occlusion was attempted (in 27 patients as a part of a multiple vessel percutaneous transluminal coronary angioplasty and in 60 patients as an isolated procedure). Primary success was achieved in 429 $(86 \%)$ cases. One or more of the major acute complications described below occurred in $34(6.8 \%)$ cases.

Life-threatening arrhythmias and death-Six $(1.2 \%)$ cases had ventricular fibrillation; in five cases
Fig 1 Angiograms ( $30^{\circ}$ right anterior oblique projection) showing acute occlusion of a side-branch after percutaneous transluminal coronary angioplasty in a 58 year old man.

(a) Shows a severe stenosis on the proximal left circumflex coronary artery (arrow) and (b) the guide wire advanced into the distal circumflex (arrow). (c) After dilatation and withdrawal of the system, the distal circumflex coronary artery is occluded either by an intimal dissection or by thrombus formation around the guide wire in the small vessel. There was no chest pain or signs of ischaemia or infarction.

during the procedure, possibly as a consequence of catheter wedging in the coronary ostium or of acute ischaemia of side-branches during catheter manipulation. It responded promptly to the re-establishment of flow, and to DC shock, and the procedure was otherwise uncomplicated, except in one case where the DC shock converted ventricular fibrillation into a supraventricular rhythm with no mechanical activity, and the patient could not be resuscitated. This was a 54 year old man with severe three vessel and bypass graft disease, poor ventricular function, and unstable angina after a repeat coronary bypass intervention. In one case ventricular fibrillation occurred about 30 minutes after the end of a 
successful procedure and responded promptly to DC shock. It was possibly caused by transient coronary spasm, which could not, however, be documented at follow up coronary angiography. Ventricular fibrillation was a complication in $3.4 \%$ of cases of chronic total coronary occlusion and $0.6 \%$ of cases with less severe lesions $(p<0.02)$.

Side-branch occlusion. In 11 cases $(1.9 \%$ of vessels and $2.2 \%$ of patients) a side-branch (fig 1) became occluded during or immediately after percutaneous transluminal coronary angioplasty. Occlusion was as common during attempts on chronic occlusions as it was during attempts on stenosis $(2.3 \%$ and $1.8 \%$ of cases, respectively). A policy of conservative management was followed in all cases. In two cases the presence of collaterals prevented the occurrence of myocardial infarction. In nine patients a rise in the activity of plasma creatine kinase indicated a myocardial infarction (mean peak 614 (328) IU/1, range 280$1200 \mathrm{IU} / 1$, normal value $<280 \mathrm{IU} / \mathrm{l}$ ).

Occlusion of a dilated vessel. Acute occlusion occurred in $30(6 \%)$ of 503 attempted stenoses $(6.8 \%$ of 440 patients at risk). In $22(73 \%)$ cases, it occurred in the catheterisation laboratory during or immediately after the procedure and in eight cases on the ward. In five of these eight it was sudden and unexpected (mean 6.2 hours from the end of the procedure (range 2-12 hours)); the other three cases had symptoms and signs of coronary occlusion 20 , 24 , and 48 hours after the procedure, within 1-3 hours of stopping intravenous heparin infusion. In $21(70 \%)$ of 30 cases of vessel occlusion there was angiographic evidence of intimal dissection at the end of the procedure (fig 2). In three cases, occlusion occurred before balloon dilatation while the guide wire was being advanced, and it was probably caused by the plaque being raised. In only one case did angiography strongly suggest coronary spasm; however, there was a poor response to intracoronary vasodilators. Repeat percutaneous transluminal coronary angioplasty re-established vessel patency without further complications. Mean luminal diameter stenosis before percutaneous transluminal coronary angioplasty in vessels with acute occlusion

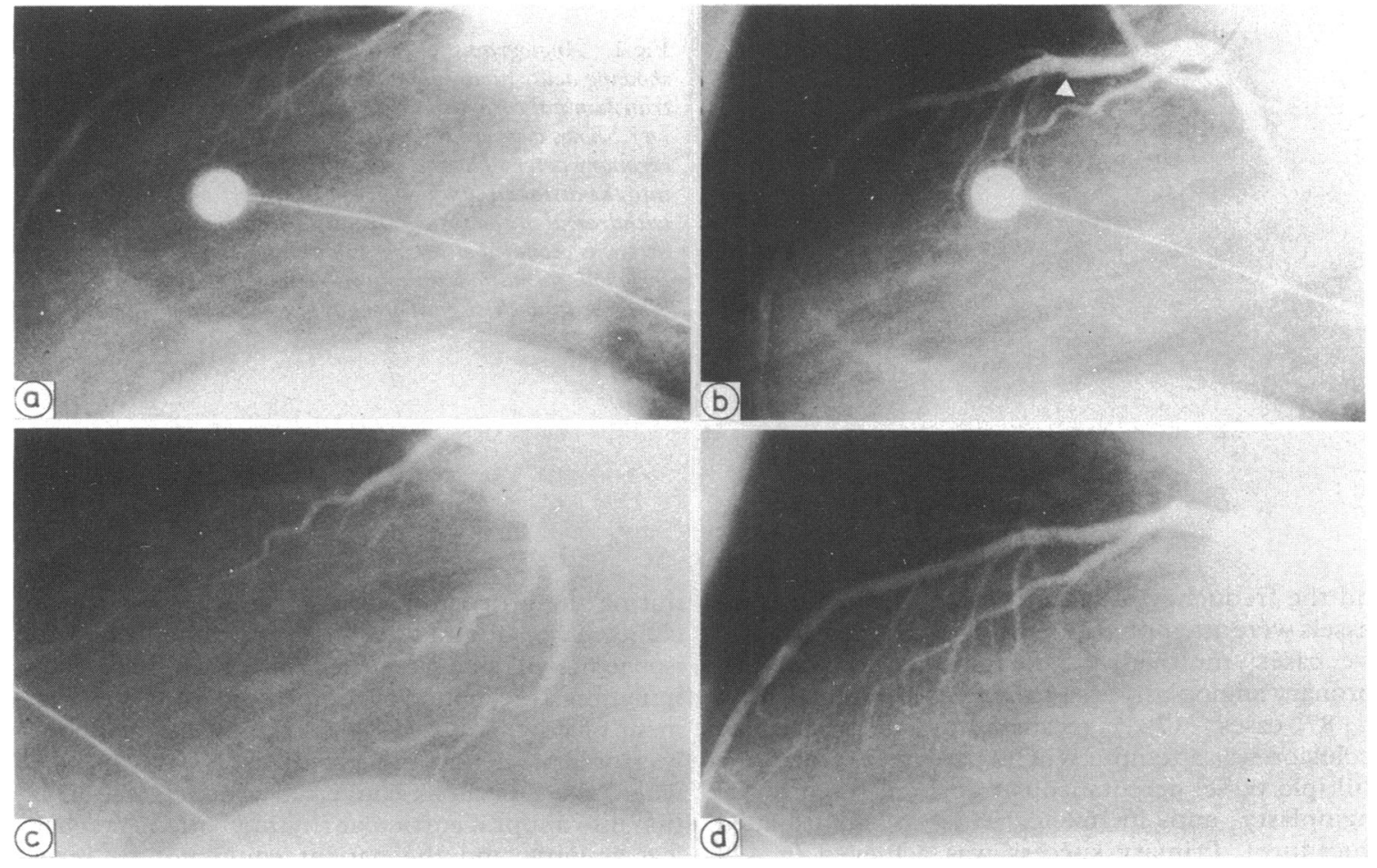

Fig 2 Angiograms (90 left lateral projection) showing acute vessel occlusion after percutaneous transluminal coronary angioplasty in a 57 year old man. (a) Severe proximal stenosis of the left anterior descending coronary artery. (b) Good angiographic result after percutaneous transluminal coronary angioplasty, with a final transstenotic gradient of $15 \mathrm{~mm} \mathrm{Hg}$. Evidence of intimal dissection (arrowhead). (c) Follow up angiogram obtained seven hours later because of sudden chest pain with ST-segment elevation in anterior leads (acute vessel occlusion). (d) Good result of emergency balloon recanalisation. 
was $86(6) \%$ compared with $80(10) \%$ in vessels without this complication $(p<0.05)$. Acute occlusion was more common (table) after dilatation of the right coronary artery $(14.3 \%)$ than the left anterior descending coronary artery $(4.2 \%)(p<$ $0.02)$ and the circumflex coronary system $(2 \cdot 7 \%)$ (p $<0.01$ ), with no significant difference between the last two arteries. The mean luminal diameter stenosis before percutaneous transluminal coronary angioplasty was not significantly different for the three vessels. The frequency of acute occlusion of a coronary vessel was not significantly different in men and in women $(6.5 \%$ and $2.9 \%$, respectively) or in patients with New York Heart Association class IV angina and with less severe angina $(4.6 \%$ and $6.4 \%$, respectively). The frequency of occlusion of a coronary vessel or side-branch was not significantly different in multivessel and in single-vessel percutaneous transluminal coronary angioplasty procedures (9.4\% and $8 \%$ respectively). Emergency repeat percutaneous transluminal coronary angioplasty (figs 1 and 3) was attempted in 24 cases and in four of them an intracoronary infusion of streptokinase was also given to restore patency of the occluded vessel. Emergency repeat percutaneous transluminal coronary angioplasty was performed in 20 of 22 cases of occlusion in the catheterisation laboratory and in four of eight cases of delayed occlusion on the ward. Recanalisation was successful in eight $(33 \%)$ patients, three of whom nevertheless sustained an acute myocardial infarction.

Emergency bypass surgery (fig 3 ) was performed in eight cases $(1.6 \%$ of all procedures and $1.8 \%$ of patients at risk). In three patients it was not preceded by attempted recanalisation: one of these patients had

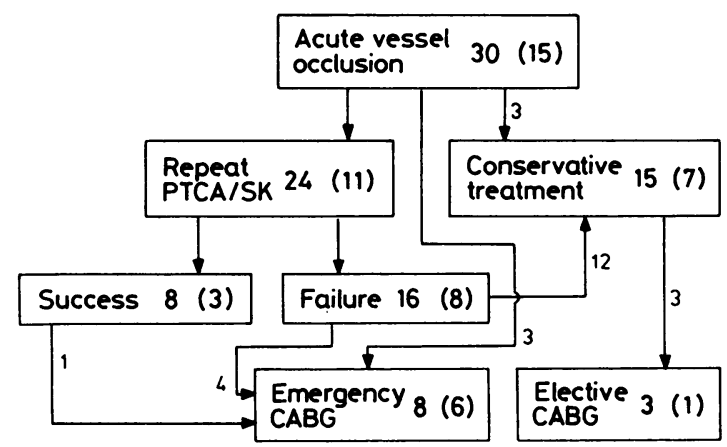

Fig 3 Chart showing how acute vessel occlusion after percutaneous transluminal coronary angioplasty (PTCA) was treated. The total number of patients is indicated for each box and numbers crossing over are shown. Figures in parentheses indicate number of patients with evidence of acute myocardial infarction during hospital stay.

$S K$, intracoronary streptokinase; $C A B G$, coronary artery bypass grafting. an acute myocardial infarction. All 5 patients who had emergency coronary surgery after attempted percutaneous recanalisation had evidence of acute infarction. The mean time from coronary occlusion to cardiopulmonary bypass for the eight patients was $197 \mathrm{~min}(120-290 \mathrm{~min})$. Six of them had enzyme evidence of acute infarction, with new $Q$ waves in three. In four cases, two or more coronary arteries were grafted. One case was complicated by cardiopulmonary arrest, acute respiratory failure, and sepsis after operation. There was no hospital death among the patients with emergency bypass surgery.

Conservative treatment was chosen for 15 patients with acute vessel occlusion without severe symptoms and signs of ischaemia because there was collateral flow and/or previous myocardial infarction in the area of the affected vessel. Seven $(50 \%)$ of these patients subsequently had a myocardial infarction. Overall, myocardial infarction occurred during attempted percutaneous transluminal coronary angioplasty in 15 of 30 cases with acute vessel occlusion, or $3.4 \%$ of procedures at risk; the mean plasma creatine kinase peak was 946 (800) IU/l (range 285-3000 IU/1, median $760 \mathrm{IU} / 1)$. On the basis of purely biochemical evidence, the mean size of myocardial infarctions caused by occlusion of a sidebranch was smaller than that caused by occlusion of a main vessel (614 (328) vs 946 (800) IU/l, p < 0.05). All patients with complications of occlusion of a main vessel or side-branch were discharged alive.

One patient had a benign coronary artery rupture ${ }^{13}$ and another needed an operation to retrieve the tip of a fractured guide wire after an otherwise successful double-vessel percutaneous transluminal coronary angioplasty. It was performed one day later and it was uneventful.

There was no significant difference between the mean age of patients with and without complications (56 (10) and 55 (9) years respectively).

\section{Discussion}

Primary success in our series $(86 \%)$ is similar to that in other recent reports ${ }^{10} 14$ in which a lower percentage of multivessel procedures were performed.

Angioplasty of isolated chronic total coronary occlusions was performed in $12 \%$ of our series. Acute reocclusion of the recanalised vessel in this setting is usually uneventful. ${ }^{15}$ Such procedures should, therefore, be excluded before calculating the frequency of major complications of procedures at risk.

The most frequent coronary vascular event in our patients after a dilatation attempt was acute occlusion of a previously patent coronary vessel. It occurred in $6.8 \%$ of procedures at risk in our series. Acute vessel 
occlusion rates of about $5 \%$ were reported by the National Heart, Lung, and Blood Institute percutaneous transluminal coronary angioplasty Registry ${ }^{5}$ and the French cooperative study, ${ }^{7}$ and of $8 \%$ by other groups. ${ }^{8}$ Consistent with other reports, ${ }^{16}$ about two thirds of acute occlusions occurred within three hours of the end of the procedure in our patients. Evidence of intimal dissection at the site of dilatation was reported in $19-29 \%$ of patients after percutaneous transluminal coronary angioplasty..$^{510}$ It was shown angiographically in most of the acute occlusions in our study, which accords with other reports. ${ }^{1016}$ Other factors, such as coronary spasm or thrombosis, may contribute to acute coronary occlusion after balloon dilatation, as shown in large studies ${ }^{5}$ and in case reports. ${ }^{17}$ The contribution of these factors, however, is uncertain and angiographic evidence is often not clear cut. ${ }^{1819}$ In our series, angiographic findings were strongly suggestive of coronary spasm in one case only. This may be because intracoronary nitrates and nifedipine were used freely. Thrombosis may have contributed to occlusion of vessels in the ward when the effect of heparin was declining. In three cases angiographic evidence of thrombosis prompted the administration of intracoronary streptokinase.

Women are reported to be at a higher risk of acute coronary vascular events ${ }^{58}$ and major complications ${ }^{10}$ after percutaneous transluminal coronary angioplasty. In our study evidence supporting this finding was inconclusive. Severe and unstable angina was also associated with a higher frequency of acute coronary vascular events in the patients of the National Heart, Lung, and Blood Institute percutaneous transluminal coronary angioplasty Registry ${ }^{5}$ but not in ours. Our finding is consistent with that of other reports. ${ }^{10}$ In our series more severe lesions were more liable to acute occlusion after percutaneous transluminal coronary angioplasty. This accords with evidence from the United States registry ${ }^{5}$ but not with other reports. ${ }^{10}$ In our series lesions of the right coronary artery were more liable to acute occlusion than lesions in other vessels, despite similar degrees of luminal stenosis before percutaneous transluminal coronary angioplasty. This was not reported in other series. ${ }^{8}$ Both univariate and multivariate analysis of data from the United States registry showed that intimal dissection was significantly more common after percutaneous transluminal coronary angioplasty of the right coronary artery. Percutaneous transluminal coronary angioplasty of the right coronary artery, however, was neither a predictor of acute coronary occlusion ${ }^{5}$ nor of overall non-fatal complications. ${ }^{4}$

The frequency of acute vessel occlusion in our patients who had a multivessel procedure was not significantly higher than in those who had single- $c$. vessel lesions. In about a third of our patients having $\vec{\Rightarrow}$ a multivessel procedure recanalisation of a chronic $\stackrel{5}{+}$ total occlusion was attempted.

The treatment of acute coronary occlusion after an angioplasty attempt has probably changed in several $\frac{\bar{m}}{\vec{D}}$ centres over the past ten years and remains con- $\propto$ troversial. In earlier series ${ }^{71420-22}$ emergency coronary $\%$ bypass surgery was performed in $4.8-13 \%$ of $\vec{\circ}$ patients in whom percutaneous transluminal coronary angioplasty was attempted and the frequency in $\vec{\omega}$ the National Heart, Lung, and Blood Institute $\frac{\mathscr{S}}{\sigma}$ percutaneous transluminal coronary angioplasty Registry was $6.6 \% .{ }^{23}$ More recent reports show a 0 decline in emergency coronary surgery to $2 \%$, along i with an increase in the frequency of acute myocardial $\vec{G}$ infarction without emergency surgery. ${ }^{10}$ Insertion of ${ }_{\circ}$ an intra-aortic balloon for counterpulsation before $\mathrm{S}$ emergency surgery has also been recommended for $\vec{T}$ patients with severe ischaemia. ${ }^{24}$ The choice of $\mathbb{O}$ treatment for acute vessel occlusion after percutaneous transluminal coronary angioplasty depends on several factors. Where percutaneous transluminal coronary angioplasty is performed between ${ }^{\circ}$ scheduled bypass operations an operating room may not be available if emergency surgery is needed some time after the end of an initially successful percutaneous transluminal coronary angioplasty procedure. ${ }^{20} \mathrm{O}$ About $40-60 \% \%^{102123-25}$ of patients who have emergency coronary surgery after percutaneous tran- $\mathbb{D}$ sluminal coronary angioplasty have evidence of $\overrightarrow{\overrightarrow{0}}$ myocardial infarction, despite prompt operation, and 3 mortality ranges from $0-6.4 \% \cdot{ }^{1021-2325}$ Emergency repeat percutaneous transluminal coronary angio-? plasty or intracoronary streptokinase or both have $\frac{\bar{\sigma}}{\sigma}$

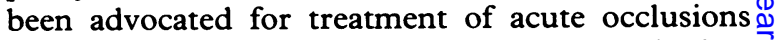
after percutaneous transluminal coronary angioplas $-\frac{7}{\sigma}$ ty.$^{15}$ About a third of patients undergoing emergency 3 . recanalisation attempts and all patients requiring subsequent emergency coronary surgery showed evidence of a new myocardial infarction. ${ }^{15}$ Vessel $\mathrm{O}$ recanalisation was attempted in most of our patients, and emergency coronary surgery was the first choiceo in only three cases. Whatever the first and subsequent treatments, half of our cases with acute vessel occlusion had evidence of myocardial infarction. N Side-branch occlusion, caused by either a snow-N plough effect at the site of balloon inflation or by intimal injury or thrombosis by the guide wire (fig 1) was seen in about $2 \%$ of our patients, which is similar $\frac{\text { C }}{\bar{D}}$ to previous reports. ${ }^{1026}$ Most cases had enzyme $\stackrel{\rho}{\rightarrow}$ evidence of acute infarction. Although the specificity of the increases in plasma creatine kinase as a markero of myocardial necrosis after transient coronary occlusions has recently been questioned, ${ }^{2728}$ we used $\vec{\nabla}$ it for definition of myocardial infarction. The overall 
frequency of infarction in our series was $4.8 \%$ and this compares favourably with that in other series, ${ }^{57}$ but it is higher than the $2.6 \%$ reported by the Emory University group which used a new $Q$ wave as the criterion for diagnosis. ${ }^{10}$

In a large series ventricular fibrillation occurred in $1.5 \%$ to $2.9 \%$ of patients during percutaneous transluminal coronary angioplasty ${ }^{610}$; it is usually responsive to DC shock and recovery is uneventful-it is not usually regarded as a major complication. It occurred in $1.2 \%$ of our patients. In patients who have percutaneous transluminal coronary angioplasty for chronic total coronary occlusion ventricular fibrillation is more common because vigorous and persistent attempts on the occlusions cause temporary compromise of adjacent side branches and predispose the heart to electrical instability. Ventricular fibrillation was seen in the only patient in our series who died; however, the cause of death was ischaemic left heart failure. Our mortality rate $(0.2 \%)$ is within the reported range of $0 \cdot 1^{10}$ to $1 \cdot 3 \%{ }^{8}$

Elective percutaneous transluminal coronary angioplasty performed by experienced operators with modern steerable dilatation systems has a high primary success rate and a reasonably low mortality rate. Complications, usually myocardial infarction caused by acute vessel occlusion, occur in about one out of 14 procedures. Efforts should be directed to improving the treatment of acute vessel occlusion to prevent or limit myocardial necrosis.

\section{References}

1 Gruentzig AR. Transluminal dilatation of coronaryartery stenosis. Lancet 1978;i:263.

2 Freudenberg H, Lichtlen PR, Engel HJ. Zur tranluminalen Angioplastie von Koronargefässen; Analyse der wichtigsten Komplikationen aufgrund postmortaler Untersuchungen am menschlichen Herzen. Z Kardiol 1981;70:39-44.

3 Schofer J, Krebber HJ, Bleifeld W, Mathey DG. Acute coronary artery occlusion during percutaneous transluminal coronary angioplasty: reopening by intracoronary streptokinase before emergency surgery to prevent myocardial infarction. Circulation 1982;66:1325-31.

4 Dorros G, Cowley MJ, Simpson J, et al. Percutaneous transluminal coronary angioplasty: report of complications from the National Heart, Lung, and Blood Institute PTCA Registry. Circulation 1983;67:72330.

5 Cowley MJ, Dorros G, Kelsey SF, Van Raden M, Detre KM. Acute coronary events associated with percutaneous transluminal coronary angioplasty. Am J Cardiol 1984;53:12C-6C.

6 Dorros G, Cowley M, Janke L, Kelsey SF, Mullin SM, Van Raden $M$. In-hospital mortality rate in the National Heart, Lung, and Blood Institute PTCA Registry. Am J Cardiol 1984;53:17C-21C.
7 Valeix B, Labrunie P, Marco J, et al. Complications de l'angioplastie coronaire transluminale. Etude multicentrique française (1983). Arch Mal Coeur 1985; 3:331-8.

8 Shiu MF, Silverton NP, Oakley D, Cumberland D. Acute coronary occlusion during percutaneous transluminal coronary angioplasty. $\mathrm{Br}$ Heart $J$ 1985; 54:129-33.

9 Meier B, Gruentzig AR. Learning curve for percutaneous transluminal coronary angioplasty: skill, technology or patient selection. Am J Cardiol 1984; 53:65C-6C.

10 Bredlau C, Roubin GS, Leimgruber PP, Douglas JS Jr, King SB III, Gruentzig AR. In-hospital morbidity and mortality in patients undergoing elective coronary angioplasty. Circulation 1985;5:1044-52.

11 Weaver W, Myler RK, Sheldon WC, Houston JT, Judkins $M$, and the Laboratory Performance Standard Committee. Guidelines for physician performance of percutaneous transluminal coronary angioplasty. Cathet Cardiovasc Diagn 1985;11:109-12.

12 Meier B, Rutishauser W. Transluminal coronary angioplasty-state of the art 1984. Acta Med Scand 1985;701(suppl):142-7.

13 Meier B. Benign coronary perforation during percutaneous transluminal coronary angioplasty. $\mathrm{Br}$ Heart $\mathrm{J}$ 1985;54:33-5.

14 Kober G, Vallbracht C, Lang H, et al. Transluminale koronare Angioplastik 1977-1985. Erfahrungen bei 1000 Eingriffen. Radiologe 1985;25:346-53.

15 Melchior JP, Meier B, Urban P, et al. Percutaneous transluminal coronary angioplasty for chronic total coronary arterial occlusion. Am J Cardiol 1987;59: 535-8.

16 Hollman J, Gruentzig AR, Douglas JS, King SB III, Ischinger T, Meier B. Acute occlusion after percutaneous transluminal coronary angioplasty-a new approach. Circulation 1983;68:725-32.

17 Ischinger T, Zack $P$, Aker U. Acute coronary occlusion during balloon angioplasty due to intracoronary thrombus and coronary spasm: a reversible complication. Am Heart J 1984;107:1271-5.

18 Hollman J. Acute occlusion syndrome post PTCA [Letter]. Am Heart J 1984;107:1403.

19 Ischinger T. Reply [Letter]. Am Heart $J$ 1984;107:1403.

20 Murphy DA, Craver JM, Jones EL, Gruentzig AR, King SB III, Hatcher CR Jr. Surgical revascularization following unsuccessful percutaneous transluminal coronary angioplasty. $J$ Thorac Cardiovasc Surg 1982;84:342-8.

21 Reul GJ, Cooley DA, Hallman GL, et al. Coronary artery bypass for unsuccessful percutaneous transluminal coronary angioplasty. $J$ Thorac Cardiovasc Surg 1984;88:685-94.

22 Akins CW, Block PC. Surgical intervention for failed percutaneous transluminal coronary angioplasty. $\mathrm{Am}$ J Cardiol 1984;53:108C-11C.

23 Cowley MJ, Dorros G, Kelsey S, Van Raden M, Detre KM. Emergency coronary bypass surgery after coronary angioplasty: the National Heart, Lung, and Blood Institute's percutaneous transluminal coronary 
angioplasty Registry experience. Am J Cardiol 1984;53:22C-6C.

24 Murphy DA, Craver JM, Jones EL, et al. Surgical management of acute myocardial ischemia following percutaneous transluminal coronary angioplasty. Role of intra-aortic balloon pump. $J$ Thorac Cardiovasc Surg 1984;87:332-9.

25 Golding L, Loop F, Hollman J, et al. Early results of emergency surgery after coronary angioplasty. Circulation 1986;74(suppl III): III-26-9.
26 Meier B, Gruentzig AR, King SB III, et al. Risk of side branch occlusion during coronary angioplasty $\Rightarrow$ Am J Cardiol 1984;53:10-4.

27 Heyndrickx GR, Amano J, Kenna T, et al. Creatine kinase release not associated with myocardial necrosisō after short periods of coronary artery occlusion in $\frac{\bar{c}}{\bar{s}}$ conscious baboons. J Am Coll Cardiol 1985;6:1299-市 303.

28 Fishbein MC. Creatine kinase release after brief coronary occlusion. J Am Coll Cardiol 1985;6:1304-5. 